\title{
Transforming ellipsoidal heights and geoid undulations between different geodetic reference frames
}

\author{
Christopher Kotsakis
}

Published online: 4 September 2007

(C) Springer-Verlag 2007

\section{Erratum to: J Geod}

\section{DOI 10.1007/s00190-007-0174-9}

The original version of this article unfortunately contained a few minor mistakes:

1) Right after Eq. (6), the symbol ' $M$ ' should NOT be in italics.

2) At the left hand-side of Eqs. (18) and (19), the symbol ' $N$ ' should be in italics.

3) In Table 1 the following corrections occurred:

- 'GRF trtanslation terms' should be changed to 'GRF translation terms'
- there should be an empty line before the 'GRF translation terms'

- there should not be an empty line between the equations $\delta h\left(t_{x}\right)=\ldots$ and $\delta h\left(t_{y}\right)=\ldots$

- there should be an empty line before the 'GRF orientation terms'

- there should not be an empty line between the equations $\delta h\left(\varepsilon_{x}\right)=\ldots$ and $\delta h\left(\varepsilon_{y}\right)=\ldots$

- there should be an empty line before the 'GRF scaling term'

- there should not be an empty line between the equations $\delta h(\delta a)=\ldots$ and $\delta h(\delta f)=\ldots$

The online version of the original article can be found under doi:10.1007/s00190-007-0174-9.

\section{Kotsakis $(\bowtie)$}

Department of Geodesy and Surveying,

Aristotle University of Thessaloniki,

University Box 440, 54124 Thessaloniki, Greece

e-mail: kotsaki@ topo.auth.gr 